\title{
Spiroplasma mirum, a New Species from the Rabbit Tick (Haemaphysalis leporispalustris)
}

\author{
JOSEPH G. TULLY, ${ }^{1}$ ROBERT F. WHITCOMB,${ }^{2}$ DAVID L. ROSE, ${ }^{1}$ AND JOSEPH M. BOVÉ ${ }^{3}$ \\ Laboratory of Infectious Diseases, National Institute of Allergy and Infectious Diseases, Bethesda, Maryland \\ $20205^{1}$; Plant Protection Institute, Science and Education Administration, U.S. Department of Agriculture, \\ Beltsville, Maryland 207052; Laboratoire de Biologie Cellulaire et Moléculaire, Institute National de \\ Recherche Agronomique, and University of Bordeaux II, F-33I40 Pont-de-la-Maye, France ${ }^{3}$
}

\begin{abstract}
Three spiroplasma strains recovered from rabbit ticks (Haemaphysalis leporispalustris) in Georgia and Maryland were found to be similar in biochemical, serological, and pathological properties. The organisms grew at temperatures of 20 to $37^{\circ} \mathrm{C}$, required cholesterol for growth, fermented glucose, hydrolyzed arginine, and produced a film and spot reaction. The three spiroplasma strains were serologically distinct from the one established species (Spiroplasma citri) in the genus and from all other unclassified spiroplasma serogroups presently known. On the basis of these findings and other morphological, biological, and serological properties of the organism, it is proposed that spiroplasma strains with these characteristics be classified as a new species, Spiroplasma mirum. Strain SMCA (ATCC 29335) is the type strain.
\end{abstract}

While searching for rickettsiae in ticks in 1964, Clark discovered a filterable agent that multiplied in embryonated chicken eggs and induced cataracts in young rodents (9-11). Clark termed the organism the suckling mouse cataract agent (SMCA) in recognition of the highly characteristic ocular syndrome that it induced in rats and mice. In the early studies, because it was filterable, the agent was thought to be a virus $(9,11)$. Also, it did not grow in artificial media or in cell cultures $(9-11,17)$. It was not until 1973 that observations of pleomorphic bodies in ultrathin sections of rat and mouse retina or pelleted egg fluids suggested that the agent might be a mycoplasma $(3,44)$. Discovery of the true microbial identity of the tick-derived agent came with the discovery of spiroplasmas. In 1973, Spiroplasma citri, the only existing named species of the genus, was described (29). Recognition of the existence of a genus of helical wallless mycoplasmas associated with arthropods and plants prompted reexamination of the status of SMCA. Examination of infected egg fluids by dark-field microscopy revealed helical filaments which electron microscopy showed to be devoid of cell wall or periplasmic fibrils (38). Complement fixation and precipitin ring serological tests demonstrated a low order of cross-reactivity with $S$. citri (37). Thus, the SMCA was not a spirochete (7) or a bacterial agent but a spiroplasma (38). Cultivation of the SMCA in cellfree SP-4 medium was accomplished in 1977 , and triply cloned organisms grown in this medium induced the typical experimental disease syndrome in suckling rats (37). Earlier, the sero- logical identity of a second strain (GT-48) with SMCA was established (38). Later, a third strain was isolated from rabbit ticks in Maryland (31a). Cultivation and general distribution of SMCA and related strains stimulated efforts in several laboratories to characterize the agent further. The nature of the SMCA genome was determined $(4,22$; J. M. Bové, Assoc. Coord. Tech. Agric. [Paris], in press), and the pattern of its cell proteins was compared with those of proteins from other spiroplasmas by polyacrylamide gel electrophoresis (26). Although the sum total of these characteristics seemed to indicate that the SMCA represented a new Spiroplasma species, publication of a taxonomic description was deferred for several reasons. The most compelling was the collective judgment of many investigators that the designation of a new Spiroplasma species should await more adequate comparative studies, particularly serological analysis, of the large number of new spiroplasmas recovered from a variety of plant and insect sources in the past 4 years. Several of these comparative studies have now been published $(2,15,22,34,41,43)$, and all indicate that the SMCA is completely distinct from the single named species of the genus Spiroplasma. In this report, we formally propose that SMCA and related strains be recognized as a new species in the genus Spiroplasma.

\section{MATERIALS AND METHODS}

Origin of isolates. The original SMCA isolate was obtained in 1961 by inoculation of triturated suspensions of the rabbit tick (Haemaphysalis leporispalus- 
tris) into embryonated chicken eggs (9). The isolate was maintained by $\mathrm{H} \mathrm{F}$. Clark in continuous transfer through eggs for about 60 or 70 passages, and pooled allantoic fluids were stored at $-70^{\circ} \mathrm{C}$. Two pools of allantoic fluid harvested in October 1973 were received as frozen material in April 1974. One of the pools, representing the SMCA strain, was inoculated into the yolk sacs of 7-day-old chicken embryos and carried through 10 additional egg passages. Allantoic fluid from the second egg passage was inoculated into a variety of spiroplasma culture media in June 1975. Growth occurred in SP-4 medium (37) at both 30 and $37^{\circ} \mathrm{C}$, and the spiroplasmas were purified by conventional $3 \mathrm{X}$ filtration-cloning techniques (32). The GT-48 strain, which had been isolated from rabbit ticks collected in Georgia at the time of the SMCA isolation (9), was carried through similar egg passages, cultivated in SP-4 broth medium, and purified by filtrationcloning. The TP-2 strain, on the other hand, was isolated directly from macerated rabbit ticks collected in Maryland in 1978 and cultured in SP-4 medium (31a). This strain was also cloned three times.

Several other spiroplasmas were employed in comparative tests with the SMCA group of isolates. These included the type strain (Maroc $=\mathrm{R} 8 \mathrm{~A} 2)$ of $S$. citri (ATCC 27556), the E275 strain (ATCC 33220) of corn stunt spiroplasma, the BC-3 honey bee strain (ATCC 33219), the 277F tick spiroplasma (ATCC 29761), the OBMG (ATCC 33221) flower spiroplasma, and the PPS1 (ATCC 33450) flower spiroplasma (39). All but the last strain were triply cloned in the Bethesda or Beltsville laboratories; each of the purified strains was directly linked to the deposited cultures by cultural lineage.

Culture media and cultivation procedures. All three strains of the SMCA group could be grown, either in primary isolation or in continuous laboratory maintenance, in SP-4 medium (31a, 37). This formulation was prepared by mixing $3.5 \mathrm{~g}$ of mycoplasma broth base (BBL Microbiology Systems, Cockeysville, Md.), $10 \mathrm{~g}$ of tryptone (Difco Laboratories, Detroit, Mich.), $5.3 \mathrm{~g}$ of peptone (Difco), and $5 \mathrm{~g}$ of glucose with $615 \mathrm{ml}$ of deionized water. The $\mathrm{pH}$ of this basal medium was adjusted to 7.6 to 7.8 . After sterilization at $121^{\circ} \mathrm{C}$ for 15 $\mathrm{min}$, the following sterile supplements were added aseptically to the cooled basal fraction: $50 \mathrm{ml}$ of CMRL 1066 tissue culture supplement $(10 \times$ with glutamine; GIBCO Laboratories, Grand Island, N.Y.), 35 $\mathrm{ml}$ of fresh yeast extract ( $25 \%$ solution; Microbiological Associates, Bethesda, Md.), $100 \mathrm{ml}$ of a $2 \%$ aqueous solution of Yeastolate (Difco), $170 \mathrm{ml}$ of fetal bovine serum preheated to $56^{\circ} \mathrm{C}$ for $1 \mathrm{~h}, 10 \mathrm{ml}$ of penicillin solution $(100,000 \mathrm{U} / \mathrm{ml})$, and $20 \mathrm{ml}$ of a $0.1 \%$ aqueous solution of phenol red. The complete medium had a final pH of 7.5 to 7.6 and an osmolality of 332 mosmol. Solid SP-4 medium was prepared by adding Noble agar (Difco) at a final concentration of $2.25 \%$. Primary isolations in the SP-4 medium were accomplished by addition of $0.1 \mathrm{ml}$ of allantoic fluid from infected eggs to $2 \mathrm{ml}$ of medium, followed by incubation at $30^{\circ} \mathrm{C}$. For maintenance of the organism, cultures were passed at intervals of 4 to 5 days with $10 \%$ inocula added to fresh media. The organisms could also be adapted to other media that contained either fetal bovine serum or yeast derivatives. These included conventional mycoplasma medium containing $20 \%$ horse serum (20) and M1A (21, 42). A simplified variation of the latter medium, the M1B formulation, in which fetal bovine serum was replaced by $5 \%$ bovine serum fraction (Difco), was used for determination of the biochemical properties of SMCA. This medium was prepared by mixing $7 \mathrm{~g}$ of mycoplasma broth base, $3.3 \mathrm{~g}$ of tryptone, $2.7 \mathrm{~g}$ of peptone, and $30.8 \mathrm{~g}$ of sorbitol with $500 \mathrm{ml}$ of deionized water. After this basal fraction was sterilized for $25 \mathrm{~min}$ at $121^{\circ} \mathrm{C}$ and cooled, the following sterile supplements were added aseptically: $33 \mathrm{ml}$ of a $25 \%$ solution of fresh yeast extract, $50 \mathrm{ml}$ of a $4 \%$ solution of Yeastolate, 50 $\mathrm{ml}$ of bovine serum fraction, $5 \mathrm{ml}$ of penicillin solution $(100,000 \mathrm{U} / \mathrm{ml}), 4 \mathrm{ml}$ of a $0.5 \%$ solution of phenol red, $200 \mathrm{ml}$ of amino acid mixture, and $150 \mathrm{ml}$ of an organic acid and inorganic salt mixture. The $\mathrm{pH}$ of this supplement was adjusted to 7.4 , and the fraction was sterilized by filtration through $220-\mathrm{nm}$ membrane filters. The amino acid mixture was prepared by mixing $1.25 \mathrm{~g}$ of $\beta$-alanine, $1 \mathrm{~g}$ of $\mathrm{L}$-arginine, $1 \mathrm{~g}$ of $\mathrm{L}$-aspartic acid, $0.15 \mathrm{~g}$ of L-cysteine, $0.25 \mathrm{~g}$ of L-cystine, $0.2 \mathrm{~g}$ of $\mathrm{L}$ glutamic acid, $4.5 \mathrm{~g}$ of L-glutamine, $0.625 \mathrm{~g}$ of glycine, $1 \mathrm{~g}$ of L-histidine, $0.375 \mathrm{~g}$ of L-isoleucine, $0.375 \mathrm{~g}$ of Lleucine, $4.125 \mathrm{~g}$ of L-lysine $\mathrm{HCl}, 2 \mathrm{~g}$ L-methionine, $0.375 \mathrm{~g}$ of $\mathrm{L}$-phenylalanine, $4.25 \mathrm{~g}$ of $\mathrm{L}$-proline, $0.625 \mathrm{~g}$ of L-serine, $0.875 \mathrm{~g}$ of $\mathrm{L}$-threonine, $0.25 \mathrm{~g}$ of $\mathrm{L}$ tryptophan, $1.25 \mathrm{~g}$ of L-tyrosine, and $0.75 \mathrm{~g}$ of $\mathrm{L}$-valine per liter of deionized water. It was necessary to dissolve tyrosine in warm $1 \mathrm{~N} \mathrm{NaOH}$ and to dissolve cystine in $1 \mathrm{~N} \mathrm{HCl}$, and to add the dissolved acids slowly with mixing to the otherwise complete amino acid fraction. The organic acid-inorganic salt fraction consisted of $7 \mathrm{~g}$ of $\mathrm{NaCl}, 2.3 \mathrm{~g}$ of $\mathrm{Na}_{2} \mathrm{HPO}_{4}, 1.5 \mathrm{~g}$ of $\mathrm{KH}_{2} \mathrm{PO}_{4}, 5.3 \mathrm{~g}$ of $\mathrm{KCl}, 6.0 \mathrm{~g}$ of $\mathrm{MgSO}_{4}$ (anhydrous), $0.67 \mathrm{~g}$ of $\alpha$-ketoglutaric acid, $0.33 \mathrm{~g}$ of succinic acid, $0.33 \mathrm{~g}$ of fumaric acid, and $0.33 \mathrm{~g}$ of malic acid per liter. Appropriate amounts of the test substrate were added to this formulation for determination of biochemical activities of the test organisms.

Filtration studies. An SP-4 broth culture of the SMCA strain that had been incubated for 5 days at $30^{\circ} \mathrm{C}$ was examined for passage through a series of membrane filters with graded pore diameters $(450,300$ and $220 \mathrm{~nm}$ ). At least $5 \mathrm{ml}$ of culture fluid containing SMCA was passed through a sterile membrane filter by means of a hypodermic syringe and minimum hand pressure. Each filtrate was titrated in a series of 10 fivefold dilutions in SP-4 broth, and all dilution tubes were incubated at $30^{\circ} \mathrm{C}$. At the end of 3 weeks, the tubes were examined for growth by recording color change and turbidity. In each series, broth in the last tube showing turbidity was examined by dark-field microscopy to confirm the presence of helical forms. At least two of the next tubes in the dilution series were also checked microscopically to confirm the absence of growth. The passage of SMCA through the various filters was recorded as the last fivefold dilution tube showing growth of helical forms and a color change, expressed in color-changing units (CCU) per milliliter.

Morphology. Cultures of the SMCA and TP-2 strains were routinely monitored by dark-field microscopy. Techniques for study of cellular morphology and ultrastructure by electron microscopy have been published previously (14).

Temperature requirements. Temperature requirements were determined by inoculating SP- 4 broth with SMCA culture to give about $10^{6} \mathrm{CCU} / \mathrm{ml}$ and incubat- 
ing the cultures at $37,32,30,25$, and $20^{\circ} \mathrm{C}$. At subsequent intervals, growth was assessed by titration in a series of 10 -fold dilution tubes for determination of CCU per milliliter. As before, each of the dilution series was evaluated by examination of the dilutions near the endpoint by dark-field microscopy.

Sterol requirement. The growth response to cholesterol was determined by a technique modified slightly from the recommended direct broth culture method (28). All three spiroplasma strains in this group (SMCA, GT-48, and TP-2) grew well only in SP-4 broth containing the CMRL 1066 tissue culture supplement. This supplement, however, contained small amounts of cholesterol, so the "serum free" base medium for the sterol test also contained a small residual of available cholesterol (final concentration, $0.1 \mu \mathrm{g} / \mathrm{ml}$ ). Seven individual flasks of this base medium were prepared and supplemented with palmitic acid, albumin, Tween 80, and four levels of cholesterol solubilized in $95 \%$ ethanol. The materials and concentrations employed were similar to those noted in the recommended procedure (28). Each medium preparation was distributed in a series of 10 culture tubes ( 4.5 $\mathrm{ml}$ per tube). Tubes of base medium supplemented with various concentrations of fetal bovine serum were included as controls. The first tube in each series was inoculated with $0.5 \mathrm{ml}$ of a 1:10 dilution of a 6-day-old culture of SMCA grown in SP-4 medium. The diluent for the inoculum was the "serum-free" base medium. Tenfold dilutions were made in each series, and all tubes were incubated at $30^{\circ} \mathrm{C}$. At weekly intervals, the amount of growth in each dilution series was graded by noting turbidity or color changes, or both, in the medium. Again, confirmation of growth was made by sampling selected tubes in each series and examining the culture fluids by dark-field microscopy for helical forms.

Biochemical tests. Because organisms in this group failed to grow in conventional serum fraction medium, tests for substrate utilization were performed in the M1B medium, a modification of M1A in which fetal bovine serum was replaced by $5 \%$ bovine serum fraction. All isolates of the group grew in this medium, eventually producing an indicator change as the medium acidified. Presumably, this indicator change reflected fermentation of substances present in the yeast derivatives or in the mycoplasma broth base components of the medium. Utilization of substrates was assessed by observing indicator changes that occurred prior to the indicator change of control tubes that received the same inoculum but did not contain test substrate. At least four fivefold dilution series were performed with each substrate, and the tests were repeated at three separate intervals. The results were scored on the basis of the amount of similarity in the responses of the replicate tests. In all substrate utilization tests, the Maroc strain of $S$. citri was used as a "control." Inclusion of this control revealed an inherent difficulty in the test procedures. In the M1B medium, $S$. citri grew with such rapidity, fermenting substances in the basal medium, with acid production, that the fermentation of the test substrate was obscured. For example, S. citri produced an indicator change in M1B medium in approximately the same time interval whether or not glucose was present in the medium. In contrast, strains of corn stunt spiroplasma, which grows more slowly, could be shown to ferment glucose and fructose. The ability of the SMCA and TP- 2 strains to catabolize 12 carbohydrates, at concentrations that varied from 0.1 to $2 \%$, was assessed by the above-mentioned method.

Certain spiroplasmas may utilize arginine only in the presence of glucose or other substrates (33). Our tests for arginine utilization, therefore, included test media that controlled these possibilities. Variations in the M1B medium were prepared as follows: (i) standard carbohydrate composition, but without arginine, glucose, or any of the defined amino acids of the formula; (ii) without carbohydrates or glucose, but with a full complement of amino acids, including arginine at a $1 \%$ concentration; (iii) without carbohydrates other than $1 \%$ glucose, and with $1 \%$ arginine; and (iv) no carbohydrates, arginine, or glucose. The SMCA and TP-2 strains were inoculated into each medium, and three fivefold dilutions were prepared. All tubes were incubated at $30^{\circ} \mathrm{C}$ and observed daily for indicator change.

Complete M1B medium was also supplemented with urea to give a final concentration of $1 \%$. A series of four fivefold dilutions of SMCA or TP- 2 in this medium was prepared, and the tubes were observed for 3 weeks for indicator changes at an incubation temperature of $30^{\circ} \mathrm{C}$.

Tests for film and spot reactions, phosphatase activity, tetrazolium reduction, serum digestion, and hydrolysis of arbutin were performed on solid SP-4 medium by techniques previously described $(1,5,16)$. Susceptibility of the SMCA and TP-2 strains to digitonin was assayed by a plate method, with the SP-4 agar medium (18). Hemadsorption of guinea pig erythrocytes to agar colonies of the two strains was tested by a technique previously described (24).

Serological tests. Hyperimmune antisera to the two spiroplasma strains were prepared as described earlier (36). Disk growth inhibition tests were performed with spiroplasmas grown in either M1A or SP-4 agar medium. Antigens grown in broth were usually diluted to $10^{-3}$ of the original culture, which is equivalent to about $10^{5}$ colony-forming units per milliliter for each spiroplasma. Techniques for the deformation/metabolism inhibition tests have been published $(41,43)$.

\section{RESULTS}

Morphological and cultural properties. In SP-4 broth, or in fluids of infected eggs, organisms of the SMCA group examined by dark-field microscopy were seen as helical filaments 3 to $8 \mu \mathrm{m}$ long and 0.1 to $0.2 \mu \mathrm{m}$ in diameter. In rapidly growing cultures in the logarithmic phase of growth, a predominance of short helical filaments was noted. However, in the stationary phase of growth, or in suboptimal media, the organisms became spheroidal. Flexing and twitching of the cells was frequently observed in broth cultures containing helical forms, and some cells exhibited apparent rotatory motility. Negatively stained preparations of the organisms not only showed similar structural features but also revealed that one end of the helix was more pointed than the other. Neither negatively stained nor sectioned organisms showed periplasmic fibrils or any evidence of cell wall 
material $(37,38)$. Instead, thin sections showed only a typical unit membrane without evidence of a surrounding envelope. Examination of negatively stained preparations of organisms revealed that some cells carried spiroplasma viruses. Members of the group have been found to be infected with both the $\mathrm{C} 1$ and $\mathrm{C} 3$ virus groups (13).

Primary isolation of the organisms was best achieved in SP-4 medium. This formulation, which has also proved useful for primary isolation of other mycoplasmas (35), probably owes its efficacy to the tissue culture supplement (CMRL 1066) incorporated into the medium. Omission of the CMRL 1066 component in SP-4 broth, for example, blocked isolation in all of 25 primary isolation attempts in which $0.2 \mathrm{ml}$ of infected allantoic fluids was added to $1.8 \mathrm{ml}$ of incomplete broth. In contrast, all 25 specimens of infected egg fluids added to complete SP-4 medium yielded helical forms.

Primary isolates of the organism were first evidenced by the appearance of a light turbidity and the presence of short helical filaments in the cultures. The organisms were frequently not perfectly helical in early passages, often appearing long and thin or distorted in various ways. Primary cultures and early passages were slow to acidify the SP-4 medium. Long after growth (in the form of helical filaments) was evident, gradual acidification of the cultures occurred. Eventually, the $\mathrm{pH}$ of the cultures decreased to about 5.6 but never reached the low $\mathrm{pH}$ typically observed in liquid media supporting the growth of most other spiroplasmas. All three strains in this group grew in the M1A medium but only after prior adaptation to SP-4 medium. SMCA in infected allantoic fluids could not be grown directly in M1A broth medium or in the sorbitol medium used for primary isolation of $S$. citri $(29$, 35b).

Although strains of this group formed colonies on SP-4 medium containing $0.8 \%$ Noble agar, the colonies were often diffuse and rarely, if ever, resembled the classical umbonate colonies characteristic of most mycoplasmas. Colonies on this "soft" agar appeared only after 10 to 14 days of incubation at $30^{\circ} \mathrm{C}$ in an anaerobic environment (GasPak, BBL Microbiology Systems). When $2.25 \%$ Noble agar ("hard" agar) was added to either SP-4 or M1A formulations, SMCA colonies were smaller but diffuse. Agar plates prepared by substituting $5 \%$ bovine serum fraction for the fetal bovine serum in either SP-4 or M1A "hard" agar also yielded colonies after inoculation with SMCA, GT-48, or TP-2 strains. Although most colonies on these formulations exhibited a dense core (Fig. 1A), the amount of peripheral growth around the core varied considerably, and numerous satellite colonies were observed around the central zone (Fig. 1B). The satellite growth suggested that some spiroplasma cells had migrated through the agar from the primary site of growth.

Temperature requirements for growth. The SMCA strain grew readily in SP-4 broth at temperatures between 25 and $37^{\circ} \mathrm{C}$ and achieved a growth yield of at least $10^{9} \mathrm{CCU} / \mathrm{ml}$ at each temperature (Table 1 ). At $20^{\circ} \mathrm{C}$, a growth yield of $10^{9} \mathrm{CCU} / \mathrm{ml}$ was achieved, but only after incubation for 7 days.

Reversion studies. Cultures of the SMCA, GT48 , and TP-2 strains that were maintained in antibiotic-free broth medium for at least five passages did not revert to bacterial forms. Cultures examined by dark-field microscopy were characterized by typical helical organisms, with no evidence of walled forms. Also, colonies failed to develop when platings were made on $5 \%$ sheep blood agar plates.

Filtration studies. A cloned broth culture of the SMCA strain contained $10^{8.5} \mathrm{CCU} / \mathrm{ml}$ before filtration through a series of graded membrane filters. The numbers of CCU/per milliliter after filtration through membrane filters with average pore diameters of 450,300 , and $220 \mathrm{~nm}$ were $10^{8.5}, 10^{6.5}$, and $10^{2.5}$, respectively.

Biochemical and biological properties. Biochemical reactions of the SMCA and TP-2 isolates are summarized in Tables 2 and 3. Both strains fermented glucose, but variable fermentation patterns were observed with glycerol, sucrose, trehalose, fructose, and mannose. Other carbohydrates tested gave negative reactions. Arginine hydrolysis was demonstrated for both SMCA and TP-2 strains, regardless of whether glucose was included in the test medium. However, neither fermentation of carbohydrates nor hydrolysis of arginine occurred in M1B medium from which the defined amino acid fraction had been deleted. The SMCA and TP-2 strains did not hydrolyze urea. Other biological characteristics of these two strains are summarized in Table 4. Most notable characteristics are the production of film and spot responses and susceptibility to digitonin.

Sterol requirement. The results of the modified sterol test are presented in Table 5. As noted earlier, the base medium contained a small amount of cholesterol, but significant growth of the SMCA strain was not observed in this serum-free formulation. However, increased growth was apparent in medium supplemented with albumin, palmitic acid, and Tween 80 . It should be noted, however, that the enhanced growth of the SMCA strain observed in this formulation could not be sustained for more than two consecutive passages. The addition of $1 \mu \mathrm{g}$ of cholesterol per $\mathrm{ml}$ to the base medium containing fatty acid supplements provided the most 

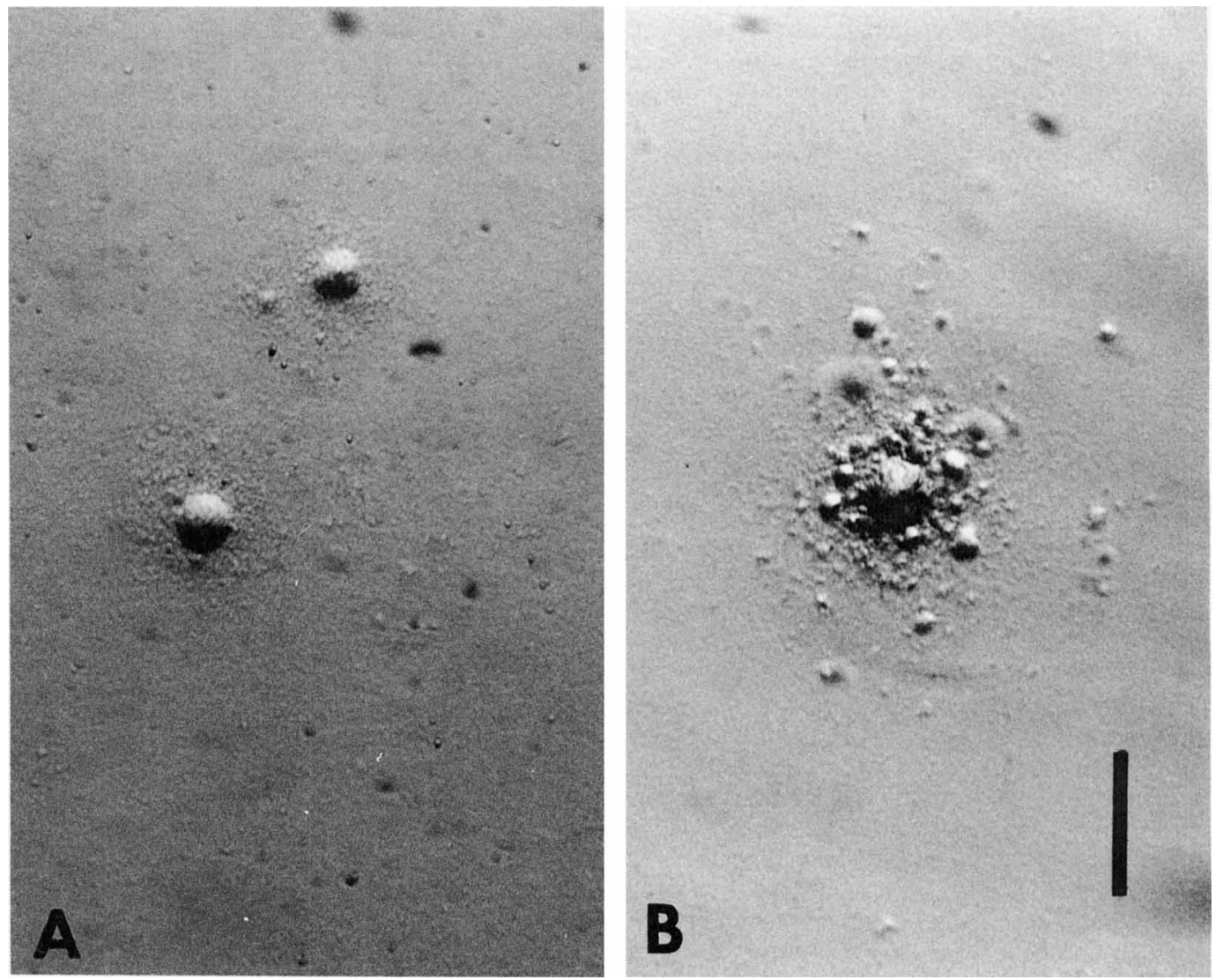

FIG. 1. Colonies of SMCA strain on SP-4 serum fraction "hard" agar after 14 days of incubation at $37^{\circ} \mathrm{C}$ in an atmosphere of $95 \% \mathrm{~N}_{2}$ plus $5 \% \mathrm{CO}_{2}$ showing (A) central core colonies and (B) satellite growth around central zones. Bar represents $100 \mu \mathrm{m}$.

significant growth stimulation of the SMCA organism. Additional amounts of cholesterol were clearly inhibitory. As expected, good growth of the SMCA strain was observed in base medium supplemented with various quantities of fetal bovine serum. These results suggest that the SMCA strain could be maintained well on SP-4 medium containing only 1 to $5 \%$ fetal bovine serum rather than the usual amount (17\%).

TABLE 1. Growth of SMCA spiroplasma at different temperatures

\begin{tabular}{ccccc}
\hline \multirow{2}{*}{ Temp $\left({ }^{\circ} \mathrm{C}\right)$} & \multicolumn{4}{c}{ Titer in CCU at day: } \\
\cline { 2 - 5 } & 0 & 3 & 5 & 7 \\
\hline 20 & $10^{6 a}$ & $10^{7}$ & $10^{8}$ & $10^{9}$ \\
25 & $10^{6}$ & $10^{7}$ & $10^{10}$ & $10^{9}$ \\
30 & $10^{6}$ & $10^{8}$ & $10^{10}$ & $10^{10}$ \\
32 & $10^{6}$ & $10^{9}$ & $10^{9}$ & $10^{9}$ \\
37 & $10^{6}$ & $10^{9}$ & $10^{8}$ & $10^{9}$ \\
\hline
\end{tabular}

${ }^{a} \mathrm{CCU}$ are defined as the reciprocal of the endpoint titer in 10-fold dilution series in SP-4 broth medium.
Serological tests. Sera prepared against SMCA and TP-2 isolates gave zones of growth inhibition ranging from 9 to $18 \mathrm{~mm}$ in reciprocal tests (Table 6). No growth inhibition was observed in reciprocal tests of the SMCA and TP-2 isolates with any strain representing an established spiroplasma serogroup, including Maroc (= R8A2), the type strain of $S$. citri. Antiserum prepared against the Drosophila sex ratio organism also failed to inhibit the growth of either SMCA or TP-2. In previously published work, strains in the SMCA group have also been compared with other established spiroplasma serogroups by both the deformation and metabolism-inhibition tests, and the results confirm the serological distinctiveness of the SMCA group $(34,41,43)$. Although the serological tests reported here did not include the GT-48 strain, previously reported studies have shown that this strain is closely related to SMCA (38). Other published serological tests also support the placement of the SMCA, GT-48, and TP-2 isolates in the genus Spiroplasma and confirm their 
TABLE 2. Utilization of carbohydrates by two strains of the SMCA group of spiroplasmas

\begin{tabular}{lccc}
\hline \multicolumn{1}{c}{ Carbohydrate $^{a}$} & Concn $(\%)$ & SMCA & TP-2 \\
\hline Glycerol & 1 & + & \pm \\
Sucrose & 2 & + & \pm \\
Trehalose & 2 & + & \pm \\
Salicin & 1 & - & - \\
Galactose & 1 & - & - \\
Cellobiose & 1 & - & - \\
Xylose & 1 & + & - \\
Fructose & 1 & + & - \\
Mannose & 1 & - & - \\
Mannitol & 1 & - & - \\
Lactose & 1 & + & - \\
Glucose & 0.1 & + & + \\
Glucose & 1 & + \\
\hline
\end{tabular}

${ }^{a}$ Substrates were added to M1B medium formulation from which carbohydrates had been omitted. Four fivefold dilutions of each inoculated spiroplasma were prepared; the experiment was performed three times. Positive reaction indicates acidification of substratecontaining medium before the control in at least $75 \%$ of replicates. Negative indicates acidification before the control in no more than $25 \%$ of replicates.

identity as strains of a new species. Complement fixation and precipitin ring tests established the existence of a low-order cross-reaction between antigens in extracts of SMCA and $S$. citri $(37$, 38). Enzyme-linked immunosorbent tests have also confirmed the unique serological position of SMCA in relation to other serogroups $(2,34)$. Thus, available data strongly suggest that the isolates of the SMCA cluster represent a serogroup that is completely distinct from all strains of the $S$. citri complex and from other serotypes that may represent putative Spiroplasma species.

\section{DISCUSSION}

Several other important characteristics of the SMCA group of strains contribute to a more complete taxonomic description of the group.
For example, a comparative study of the protein patterns of various spiroplasmas in one- and two-dimensional polyacrylamide gel electrophoresis (26) showed that SMCA differed significantly from $S$. citri and the corn stunt spiroplasma. Studies on the SMCA genome also provided significant evidence for the distinct nature of this spiroplasma group. The guanineplus-cytosine content of the deoxyribonucleic acid (DNA) of SMCA was determined to be 29 to $31 \mathrm{~mol} \%$ in several independently reported studies (4, 22; Bové, in press). Also, DNA-DNA hybridization comparisons between SMCA and $S$. citri (22) and reciprocal hybridization tests between SMCA, S. citri, and corn stunt spiroplasma (8) consistently showed SMCA to be distinct. Finally, pathogenicity of SMCA spiroplasmas for vertebrates is an important marker for the serogroup. Early egg passages of the SMCA and GT-48 isolates induced lethal infections in embryonated chicken eggs and ocular and neurological disease in suckling rats and mice (9-11). Spiroplasmas from later passages in embryonated eggs (38) or from early passages in SP-4 medium $(19,37)$ produced the same patterns of virulence. The TP-2 isolate has also been shown to induce lethal infections in embryonated eggs and cataracts in suckling rats (31a). Members of the SMCA group are also pathogenic for other insect and vertebrate hosts $(23,24 a)$.

Certain tests commonly employed in the characterization of putative members of the class Mollicutes were of limited or no utility in this study. The relatively poor growth of all isolates of this group in minimal media made certain tests difficult to perform. For example, sterol utilization was difficult to demonstrate directly on simplified variants of the SP-4 medium. More generally, all substrate utilization tests proved difficult to perform because the SMCA and TP-2 strains required either serum or yeast derivatives for growth. All of these complex medium supplements contain fermentable substances

TABLE 3. Utilization of arginine and amino acids by two strains of the SMCA spiroplasma ${ }^{a}$

\begin{tabular}{|c|c|c|c|c|c|c|c|c|c|c|}
\hline \multicolumn{5}{|c|}{ M1B medium variation } & \multicolumn{6}{|c|}{ Spiroplasma strain } \\
\hline \multirow{2}{*}{ Variation } & \multirow{2}{*}{ Carbohydrates } & \multirow{2}{*}{$\begin{array}{l}\text { Amino } \\
\text { acid } \\
\text { mix }\end{array}$} & \multirow{2}{*}{ Arginine } & \multirow{2}{*}{ Glucose } & \multicolumn{3}{|c|}{ SMCA } & \multicolumn{3}{|c|}{$\overline{\mathrm{TP}}-2$} \\
\hline & & & & & $10^{-1}$ & $10^{-1.5}$ & $10^{-2}$ & $10^{-1}$ & $10^{-2}$ & $10^{3}$ \\
\hline 1 & + & - & -- & - & $\mathbf{N}^{b}$ & $\mathrm{~N}$ & $\mathrm{~N}$ & $\mathrm{~N}$ & $\mathrm{~N}$ & $\mathrm{~N}$ \\
\hline 2 & - & + & + & - & $5 \mathrm{~B}$ & $5 \mathrm{~B}$ & $7 \mathrm{~B}$ & $6 \mathrm{~B}$ & $6 \mathrm{~B}$ & $8 \mathrm{~B}$ \\
\hline 3 & - & + & + & + & $3 \mathrm{~A} 5 \mathrm{~B}$ & $3 \mathrm{~A} 6 \mathrm{~B}$ & $3 \mathrm{~A} 8 \mathrm{~B}$ & $3 \mathrm{~A} 6 \mathrm{~B}$ & $3 \mathrm{~A} 6 \mathrm{~B}$ & $4 \mathrm{~A} 8 \mathrm{~B}$ \\
\hline 4 & - & + & -- & - & $3 \mathrm{~A}$ & $6 \mathrm{~A}$ & $6 \mathrm{~A}$ & $3 \mathrm{~A}$ & $4 \mathrm{~A}$ & $6 \mathrm{~A}$ \\
\hline
\end{tabular}

${ }^{a}$ M1B medium was prepared (1) with all amino acids deleted, (2) with all carbohydrates deleted but with $1 \%$ arginine added, (3) with all carbohydrates of the standard formulation deleted but with $1 \%$ arginine and glucose added, and (4) with all carbohydrates omitted, without supplementation by arginine or glucose.

${ }^{b}$ Indicator change: N, none; A, acidic change; B, basic change. Numbers indicate time in days before indicated change. 
TABLE 4. Miscellaneous characteristics of two strains of the SMCA group of spiroplasmas.

\begin{tabular}{|c|c|c|c|c|}
\hline \multirow{2}{*}{ Test } & \multicolumn{2}{|c|}{ Spiroplasma strain } & \multirow{2}{*}{ Positive or negative culture control } & \multirow{2}{*}{$\begin{array}{l}\text { Procedure } \\
\text { reference }\end{array}$} \\
\hline & SMCA & TP-2 & & \\
\hline Urea hydrolysis & - & - & $\begin{array}{l}\text { Ureaplasma urealyticum }(\mathrm{T}-960) \\
(+)\end{array}$ & 1 \\
\hline $\begin{array}{l}\text { Hemadsorption } \\
\text { (guinea pig } \\
\text { erythrocytes) }\end{array}$ & - & $\mathrm{ND}^{a}$ & Mycoplasma capricolum $(+)$ & 25 \\
\hline Phosphatase & + & ND & M. arginini $(-)$ & 5 \\
\hline Arbutin hydrolysis & - & - & Acholeplasma axanthum (+) & 16 \\
\hline Serum liquefaction & - & - & Mycoplasma sp. B5P (+) & 1 \\
\hline Tetrazolium reduction & + & + & M. arthritidis (-) & 1 \\
\hline Film and spot reaction & + & + & A. modicum $(-)$ & 1 \\
\hline $\begin{array}{l}\text { Digitonin } \\
\text { susceptibility }\end{array}$ & $+(9 \mathrm{~mm})$ & $+(9 \mathrm{~mm})$ & A. laidlawii $(-)$ & 18 \\
\hline
\end{tabular}

${ }^{a}$ ND, Not done.

that were eventually utilized, with concomitant acidification of the medium. Thus, substrate utilization could be assessed only by observing differences in the length of time required for medium acidification. Unequivocal patterns of utilization could be demonstrated only for glucose and arginine. Utilization of both substances has been demonstrated for a variety of spiroplasma isolates. Only the PPS1 flower spiroplasma has been reported to lack the arginine dihydrolase pathway (25). Thus, substrate utilization was not particularly useful for the separation of the SMCA isolates from other spiroplasmas because no utilization patterns appeared to be uniquely characteristic of the group.

Certain important properties support the placement of SMCA and related strains in the class Mollicutes. The possession of a trilaminar unit membrane as the sole limiting structure, lack of susceptibility to penicillin, filterability through filters with 220 -nm pore diameters, and failure to revert to walled bacteria in the absence of penicillin are characteristics shared by other members of the class. Other properties of this group (e.g., sterol dependence, helical morphology and typical motility, inability to utilize urea, and the possession of a low order of crossreactivity by serological tests that detect cytoplasmic antigens) provide clear indications that the organisms are members of the family Spiroplasmataceae, genus Spiroplasma $(29,30,32)$. Thus, we must consider the placement of members of the SMCA group at the subgeneric level.

The growth inhibition test has been used extensively for establishing species identities of Mycoplasma $(12,32)$. Comparative studies reported here and elsewhere (15; D. L. Rose, R. F. Whitcomb, and J. G. Tully, Abstr. 64, Third Conference of the International Organization for Mycoplasmology, Custer, S.D.) indicate that this serological test provides useful information for broad differentiation of spiroplasma ser- ogroups (39). In addition, the combined use of the growth inhibition test and data from the spiroplasma deformation/metabolism inhibition test distinguishes not only the major spiroplasma serogroups but also subgroups within the $S$. citri complex. These tests form the basis for a recently proposed scheme for spiroplasma classification that correlates serological data with data from composition of the spiroplasma genome (22). The serological data show that five clusters of spiroplasmas do not cross-react significantly in either growth inhibition or spiroplasma deformation/metabolism inhibition tests. One of these groups, the $S$. citri complex, is composed of at least four serological subgroups, previously designated subgroups I-1 through I-4 (41). One of these subgroups (I-4) is represented by a single

TABLE 5. Sterol requirement test for the SMCA spiroplasma

\begin{tabular}{lccccc}
\hline \multirow{2}{*}{$\begin{array}{c}\text { Cholesterol or serum } \\
\text { added to base medium }\end{array}$} & \multicolumn{5}{c}{$\begin{array}{c}\text { No. of organisms (as C CU/ml) af- } \\
\text { ter incubation at }\end{array}$} \\
\cline { 2 - 6 } & 7 & 12 & 14 & 19 & 21 \\
\hline None $^{a}$ & $10^{2}$ & $10^{2}$ & $10^{2}$ & $10^{2}$ & $10^{2}$ \\
None $^{b}$ & $10^{3}$ & $10^{5}$ & $10^{5}$ & $10^{7}$ & $10^{7}$ \\
Cholesterol $^{c}$ & & & & & \\
$1 \mu \mathrm{g} / \mathrm{ml}$ & $10^{2}$ & $10^{5}$ & $10^{7}$ & $10^{9}$ & $10^{10}$ \\
$5 \mu \mathrm{g} / \mathrm{ml}$ & $10^{2}$ & $10^{3}$ & $10^{3}$ & $10^{4}$ & $10^{4}$ \\
$10 \mu \mathrm{g} / \mathrm{ml}$ & $10^{2}$ & $10^{2}$ & $10^{3}$ & $10^{4}$ & $10^{4}$ \\
$20 \mu \mathrm{g} / \mathrm{ml}$ & $10^{2}$ & $10^{2}$ & $10^{3}$ & $10^{4}$ & $10^{4}$ \\
Fetal bovine serum $^{c}$ & & & & & \\
$0.5 \%$ & $10^{3}$ & $10^{5}$ & $10^{5}$ & $10^{7}$ & $10^{7}$ \\
$1 \%$ & $10^{4}$ & $10^{8}$ & $10^{8}$ & $10^{10}$ & $10^{10}$ \\
$5 \%$ & $10^{7}$ & $10^{10}$ & $10^{10}$ & $10^{10}$ & $10^{10}$ \\
$10 \%$ & $10^{8}$ & $10^{10}$ & $10^{10}$ & $10^{10}$ & $10^{10}$ \\
$17 \%$ & $10^{6}$ & $10^{10}$ & $10^{10}$ & $10^{10}$ & $10^{10}$ \\
\hline
\end{tabular}

a "Serum-free" base medium alone.

${ }^{b}$ Base medium with $0.5 \%$ albumin, $0.01 \%$ Tween 80 , and $10 \mu \mathrm{g}$ of palmitic acid per $\mathrm{ml}$.

c All medium preparations in these groups contained the supplements noted in footnote $b$. 
TABLE 6. Growth inhibition tests with strains of SMCA spiroplasma

\begin{tabular}{|c|c|c|c|c|c|c|c|c|}
\hline \multirow{3}{*}{ Antiserum } & \multicolumn{8}{|c|}{ Antigen } \\
\hline & \multirow{2}{*}{$\begin{array}{l}\text { S. citri } \\
\text { Maroc }\end{array}$} & \multirow{2}{*}{$\begin{array}{c}\text { Honey bee } \\
\text { spiroplasma } \\
\text { BC-3 }\end{array}$} & \multirow{2}{*}{$\begin{array}{c}\text { Corn stunt } \\
\text { spiroplasma } \\
\text { E275 }\end{array}$} & \multirow{2}{*}{$\begin{array}{c}\text { Tick } \\
\text { spiroplasma } \\
277 \mathrm{~F}\end{array}$} & \multirow{2}{*}{$\begin{array}{l}\text { Flower } \\
\text { spiroplasma } \\
\text { OBMG }\end{array}$} & \multirow{2}{*}{$\begin{array}{c}\text { Flower } \\
\text { spiroplasma } \\
\text { PPS1 }\end{array}$} & \multicolumn{2}{|c|}{$\begin{array}{c}\text { Strains of } \\
\text { SMCA group }\end{array}$} \\
\hline & & & & & & & SMCA & TP-2 \\
\hline S. citri & $16^{a}$ & 10 & 9 & 1 & 0 & 0 & 0 & 0 \\
\hline BC-3 & 12 & 12 & 12 & 2 & 0 & 0 & 0 & 0 \\
\hline E275 & 12 & 4 & 18 & 8.5 & 0 & 0 & 0 & 0 \\
\hline $277 \mathrm{~F}$ & 3 & 0 & 3 & 10 & 0 & 0 & 0 & 0 \\
\hline OMBG & 0 & 0 & 0 & 0 & 6 & 0 & 0 & 0 \\
\hline PPS1 & 0 & 0 & 0 & 0 & 0 & 6 & 0 & 0 \\
\hline SMCA & 0 & 0 & 0 & 0 & 0 & 0 & 16 & 18 \\
\hline TP-2 & 0 & 0 & 0 & 0 & 0 & 0 & 9 & 10 \\
\hline
\end{tabular}

${ }^{a}$ Diameters (in millimeters) of growth inhibition.

spiroplasma isolate derived from rabbit ticks. The $277 \mathrm{~F}$ strain, which originally derived from ticks collected in Montana in 1968 (27), was at first thought to be a spirochete. However, later morphological study (6) revealed that the agent was a spiroplasma. Subsequent studies in several laboratories clearly documented major distinctions between the $277 \mathrm{~F}$ agent and the rabbit tick-derived SMCA group, including differences in genome characteristics $(4,22$; Bové, in press), pathogenicity $(31,35 \mathrm{~b})$, and serology $(2,31,34$, 41). Group II contains the sex ratio organisms of Drosophila (40). Although these spiroplasmas have not been cultivated on artificial media, serological tests performed with antigen prepared from the hemolymph of infected insects have shown no serological cross-reactions with other spiroplasmas (40). Group III spiroplasmas, which have a guanine-plus-cytosine content of 25 to $27 \mathrm{~mol} \%$, are a cluster of flower isolates which are clearly separated by serological tests from all other spiroplasmas. Group IV spiroplasmas contain a number of isolates (34) of diverse origins, including both flowers and insects. Members of this group, although they exhibit various degrees of interrelatedness (34), are also serologically distinct from other spiroplasma serogroups and have a guanine-plus-cytosine content ( 29 to $31 \mathrm{~mol} \%$ ) that differs from those of other flower spiroplasmas (22). Finally, the SMCA, GT-48, and TP-2 strains were classified as group $\mathrm{V}$ in this classification scheme, based in part on the absence of any serological relationships to other spiroplasmas. In addition, the failure of DNA from SMCA spiroplasmas to hybridize with a DNA probe from $S$. citri (22) and the differences (26) apparent in the twodimensional electrophoresis patterns of the cell proteins of the SMCA group, when compared with other spiroplasmas, provide further evidence of the distinct nature of the SMCA group of spiroplasmas. These spiroplasmas are also clearly distinct from eight other tick-derived strains recovered recently from Ixodes pacificus (35a). Organisms of the latter group, represented by the Y32 strain, were serologically distinct from members of the SMCA group of strains and all other established spiroplasma serogroups. They have been designated as serogroup VI (35a) in the spiroplasma classification scheme noted above (22).

Thus, the SMCA, GT-48, and TP-2 isolates comprise a homogeneous cluster of organisms that is clearly distinct from the single named spiroplasma ( $S$. citri), from all members of the $S$. citri complex, and from members of all other major spiroplasma serogroups presently known. We propose that these isolates be designated Spiroplasma mirum (L. adj. mirus extraordinary). A cloned line of strain SMCA, the type strain of this organism, has been deposited in the American Type Culture Collection as ATCC 29335.

\section{REPRINT REQUESTS}

Address reprint requests to: Dr. Joseph G. Tully, Mycoplasma Section, Building 550, NIAID, Frederick Cancer Research Center, Frederick, MD 21701.

\section{LITERATURE CITED}

1. Aluotto, B. B., R. G. Wittler, C. O. Williams, and J. E. Faber. 1970. Standardized bacteriologic techniques for the characterization of Mycoplasma species. Int. J. Syst. Bacteriol. 20:35-58.

2. Archer, D. B., and J. Best. 1980. Serological relatedness of spiroplasmas estimated by enzyme-linked immunosorbent assay and crossed immunoelectrophoresis. J. Gen. Microbiol. 119:413-422.

3. Bastardo, J. W., D. Ou, and R. H. Bussell. 1974. Biological and physical properties of the suckling mouse cataract agent grown in chicken embryos. Infect. Immun. 9:444451.

4. Bové, J. M., and C. Saillard. 1979. Cell biology of spiroplasmas. p. 83-153. In R. F. Whitcomb and J. G. Tully (ed.) The Mycoplasmas, vol. 3, Plant and insect mycoplasmas. Academic Press, Inc., New York.

5. Bradbury, J. M. 1977 . Rapid biochemical tests for characterization of the Mycoplasmatales. J. Clin. Microbiol. 5:531-534.

6. Brinton, L. P., and W. Burgdorfer. 1976. Cellular and subcellular organization of the $277 \mathrm{~F}$ agent; a spiroplasma from the rabbit tick, Haemaphysalis leporispalustris (Acari:Ixodidae). Int. J. Syst. Bacteriol. 26:554-560. 
7. Canale-Parola, E. 1978. Motility and chemotaxis of spirochetes. Annu. Rev. Microbiol. 32:69-99.

8. Christiansen, C., G. Askaa, E. A. Freundt, and R. F Whitcomb. 1979. Nucleic acid hybridization experiments with Spiroplasma citri and the corn stunt and suckling mouse cataract spiroplasmas. Curr. Microbiol. 2:323-326.

9. Clark, H F. 1964. Suckling mouse cataract agent. J. Infect. Dis, 114:476-487.

10. Clark, H F, 1974. The suckling mouse cataract agent (SMCA). Prog. Med. Virol. 18:307-322.

11. Clark, H F. and L. B. Rorke. 1979. Spiroplasmas of tick origin and their pathogenicity, p. 155-174. In R. F. Whitcomb and J. G. Tully (ed.), The Mycoplasmas, vol. 3 , Plant and insect mycoplasmas. Academic Press, Inc. New York.

12. Clyde, W. A., Jr. 1964. Mycoplasma species identification based upon growth inhibition by specific antisera. $\mathrm{J}$ Immunol. 92:958-965.

13. Cole, R. M. 1979. Mycoplasma and spiroplasma viruses: ultrastructure, p. 385-410. In M. F. Barile and S. Razin (ed.), The Mycoplasmas, vol. 1, Cell biology. Academic Press, Inc., New York.

14. Cole, R. M., J. G. Tully, T. J. Popkin, and J. M. Bové 1973. Ultrastructure of the agent of citrus "stubborn disease." J. Bacteriol. 115:367--386.

15. Davis, R. E., I. M. Lee, and L. K. Basciano. 1979. Spiroplasmas: serological grouping of strains associated with plants and insects. Can. J. Microbiol. 25:861-866.

16. Ernф, H., and L. Stipkovits. 1973. Bovine mycoplasmas: cultural and biochemical studies. II. Acta Vet. Scand. 14:450-463.

17. Fabiyi, A., T. S. Elizan, and J. E. Pounds. 1971. Suckling mouse cataract agent (SMCA) in tissue culture. Proc. Soc. Exp. Biol. Med. 136:88-91.

18. Freundt, E. A., B. E. Andrews, H. Ern $\phi$, M. Kunze, and F. T. Black. 1973. The sensitivity of Mycoplasmatales to sodium-polyanethol-sulfonate and digitonin. Zentralbl Bakteriol. Parasitenkd. Infektionskr. Hyg. Abt. 1 Orig 225:104-112.

19. Friedlaender, R. P., M. F. Barile, T. Kuwabara, and H F. Clark. 1976. Ocular pathology induced by the suckling mouse cataract agent. Invest. Ophthalmol. 15:640-647.

20. Hayflick, L. 1965. Tissue cultures and mycoplasmas. Tex. Rep. Biol. Med. 23:285-303.

21. Jones, A. L., R. F. Whitcomb, D. L. Williamson, and M. E. Coan. 1977. Comparative growth and primary isolation of spiroplasmas in media based on insect tissue culture formulations. Phytopathology 47:738-746.

22. Junca, P., C. Saillard, J. Tully, O. Garcia-Jurado, J.-R Degorce-Dumas, C. Mouches, J.-C Vignault, R. Vogel, R. McCoy, R. Whitcomb, D. Williamson, J. Latrille, and J. M. Bove. 1980. Caracterisation de spiroplasmes isolés d'insectes et de fleurs de France continentale, de Corse et du Maroc. Proposition pour une classification des spiroplasmes. C.R. Acad. Sci. (Paris) 290:1209-1212.

23. Kirchhoff, H., T. Kuwabara, and M. F. Barile. 1981 Pathogenicity of Spiroplasma sp. (strain SMCA) in Syrian hamsters: clinical, microbiological, and histological aspects. Infect. Immun. 31:445-452.

24. Manchee, R. J., and D. Taylor-Robinson. 1968. Haemadsorption and hemagglutination by mycoplasmas. J. Gen. Microbiol. 50:465-478.

24a.McCoy, R. E., M. J. Davis, and R. V. Dowell. 1981. In vitro cultivation of spiroplasmas in larvae of the greater wax moth. Phytopathology 71:408-411.

25. McCoy, R. E., D. S. Williams, and D. L. Thomas. 1979. Isolation of mycoplasmas from flowers. p. 75-80. In H.-J. Su and R. E. McCoy (ed.), Proceedings of the R.O.C. United States Cooperative Science Seminar on Mycoplasma Diseases of Plants. National Science Council, Taipei, Taiwan.

26. Mouches, C., J.-C. Vignault, J. G. Tully, R. F. Whitcomb, and J. M. Bové. 1979. Characterization of spiroplasmas by one- and two-dimensional protein analysis on polyacrylamide slab gels. Curr. Microbiol. 2:69-74.
27. Pickens, E. C., R. K. Gerloff, and W. Burgdorfer. 1968. Spirochete from the rabbit tick Haemaphysalis leporispalustris (Packard). J. Bacteriol. 95:291-299.

28. Razin, S., and J. G. Tully. 1970. Cholesterol requirement of mycoplasmas. J. Bacteriol. 102:306-310.

29. Saglio, P., M. L'Hospital, D. Laflèche, G. Dupont, J. M. Bové, J. G. Tully, and E. A. Freundt. 1973. Spiroplasma citrigen and sp.n: a mycoplasma-like organism associated with "stubborn" disease of citrus. Int. J. Syst. Bacteriol. 23:191-204.

30. Skripal, I. G. 1974. On improvement of taxonomy of the class Mollicutes and establishment in the order Mycoplasmatales of the new family Spiroplasmataceae Fam. Nova. Microbiol. Zh. Kiev 36:462-467.

31. Stalheim, O. H. V., A. E. Ritchie, and R. F. Whitcomb. 1978. Cultivation, serology, ultrastructure, and virus-like particles of spiroplasma 277F. Curr. Microbiol. 1:356-370.

31a.Stiller, D., R. F. Whitcomb, M. E. Coan, and T. G. Tully. 1981. Direct isolation in cell-free medium of a spiroplasma from Haemaphysalis leporispalustris (Packard) (Acari: Ixodidae) in Maryland. Curr. Microbiol. 5:339-342.

32. Subcommittee on the Taxonomy of Mollicutes. 1979. Proposal of minimal standards for descriptions of new specie of the class Mollicutes. Int. J. Syst. Bacteriol. 29:172-180.

33. Townsend, R. 1976. Arginine metabolism of Spiroplasma citri. J. Gen. Microbiol. 94:417-420.

34. Tully, J. G., D. L. Rose, O. Garcia-Jurado, J.-C. Vignault, C. Saillard, J. M. Bové, R. E. McCoy, and D. L. Williamson. 1980. Serological analysis of a new group of spiroplasmas. Curr. Microbiol. 3:369-372.

35. Tully, J. G., D. L. Rose, R. F. Whitcomb, and R. P. Wenzel. 1979. Enhanced isolation of Mycoplasma pneumoniae from throat washings with a newly modified culture medium. J. Infect. Dis. 139:478-482.

35a.Tully, J. G., D. L. Rose, C. E. Yunker, J. Cory, R. F. Whitcomb, and D. L. Williamson. 1981. Helical mycoplasmas (spiroplasmas) from Ixodes ticks. Science 212:1043 1045.

35b.Tully, J. G., and R. F. Whitcomb. 1981. The genus Spiroplasma, p. 2271-2284. In M. P. Starr, H. Stolp, H. G. Truper, A. Balows, and H. G. Schlegel (ed.), The prokaryotes. Springer-Verlag, New York.

36. Tully, J. G., R. F. Whitcomb, J. M. Bové, and P. Saglio 1973. Plant mycoplasmas: serological relation between agents associated with citrus stubborn and corn stunt diseases. Science 182:117-120.

37. Tully, J. G., R. F. Whitcomb, H F. Clark, and D. L. Williamson. 1977. Pathogenic mycoplasmas: cultivation and vertebrate pathogenicity of a new spiroplasma. Science 195:892-894.

38. Tully, J. G., R. F. Whitcomb, D. L. Williamson, and H F. Clark. 1976. Suckling mouse cataract agent is a helica wall-free prokaryote (spiroplasma) pathogenic for vertebrates. Nature (London) 259:117-120.

39. Whitcomb, R. F. 1980. The genus Spiroplasma. Annu. Rev. Microbiol. 34:677-709.

40. Williamson, D. L., and D. F. Poulson. 1979. Sex ratio organisms (spiroplasmas) of Drosophila, p. 175-208. In R. F. Whitcomb and J. G. Tully (ed.) The Mycoplasmas, vol. 3, Plant and insect mycoplasmas. Academic Press, Inc., New York.

41. Williamson, D. L., J. G. Tully, and R. F. Whitcomb. 1979. Serological relationships of spiroplasmas as shown by combined deformation and metabolism inhibition tests. Int. J. Syst. Bacteriol. 29:345-351

42. Williamson, D. L., and R. F. Whitcomb. 1975. Plant mycoplasmas: a cultivable spiroplasma causes corn stunt disease. Science 188:1018-1020.

43. Williamson, D. L., R. F. Whitcomb, and J. G. Tully. 1978 The deformation test, a new serological method. Curr. Microbiol. 1:203-207.

44. Zeigel, R. F., and H F. Clark. 1974. Electron microscopy of the suckling mouse cataract agent: a noncultivable animal pathogen possibly related to mycoplasma. Infect. Immun. 9:430-443. 